

\title{
KarstMod: A modelling platform for rainfall - discharge analysis and modelling dedicated to karst systems
}

Naomi Mazzilli, Vincent Guinot, Hervé Jourde, N. Lecoq, David Labat, B. Arfib, Cécile Baudement, Charles Danquigny, Lucie Dal Soglio, Dominique

Bertin

\section{To cite this version:}

Naomi Mazzilli, Vincent Guinot, Hervé Jourde, N. Lecoq, David Labat, et al.. KarstMod: A modelling platform for rainfall - discharge analysis and modelling dedicated to karst systems. Environmental Modelling and Software, 2019, 122, pp.103927. 10.1016/j.envsoft.2017.03.015 . hal-01685224

\section{HAL Id: hal-01685224 https://hal.science/hal-01685224}

Submitted on 21 Jan 2018

HAL is a multi-disciplinary open access archive for the deposit and dissemination of scientific research documents, whether they are published or not. The documents may come from teaching and research institutions in France or abroad, or from public or private research centers.
L'archive ouverte pluridisciplinaire HAL, est destinée au dépôt et à la diffusion de documents scientifiques de niveau recherche, publiés ou non, émanant des établissements d'enseignement et de recherche français ou étrangers, des laboratoires publics ou privés. 


\title{
KarstMod: a modelling platform for rainfall - discharge analysis and modelling dedicated to karst systems
}

\author{
N. Mazzilli ${ }^{\mathrm{a}, *}$, V. Guinot ${ }^{\mathrm{c}}$, H. Jourde ${ }^{\mathrm{c}}$, N. Lecoq ${ }^{\mathrm{b}}$, D. Labat ${ }^{\mathrm{d}}$, B. Arfib ${ }^{\mathrm{e}}$, C. Baudement $^{\mathrm{e}}$, C. Danquigny $^{\mathrm{a}}$, L. Dal Soglio $^{\mathrm{a}}$, \\ D. Bertin ${ }^{\mathrm{f}}$ \\ ${ }^{a}$ Université d'Avignon et des Pays de Vaucluse - INRA, UMR1114 EMMAH, F-84914 Avignon, France \\ ${ }^{b}$ Normandie Université, UMR6143 CNRS M2C, F-76130 Mont-Saint-Aignan, France \\ ${ }^{c}$ HydroSciences Montpellier - UMR5569, Université de Montpellier, 34000 Montpellier, France \\ ${ }^{d}$ Géosciences Environnement Toulouse - UMR 5563 CNRS-UPS-IRD-CNES 14 Avenue Édouard Belin 31400 Toulouse \\ ${ }^{e}$ Aix Marseille Univ, CNRS, IRD, Coll France, CEREGE, Aix-en-Provence, France \\ ${ }^{f}$ GEONOSIS
}

\begin{abstract}
We propose an adjustable modelling platform (KarstMod) for both the simulation of spring discharge at karst outlets and analysis of the hydrodynamics of the compartments considered in the model. KarstMod provides a modular, userfriendly modelling environment for educational, research and operational purposes. It can reproduce the structure of most conceptual lumped models of karst systems in the literature. The modularity of the platform allows to compare different hydrosystems within the same methodological approach. To promote good modelling practices, the platform provides a variety of graphs and tools that facilitate improved understanding and insights in the behaviour of the models, and that detect possible flaws in structure and parameterization. The model and users manual are freely downloadable from the SNO Karst website (www.sokarst.org)
\end{abstract}

Keywords: Data visualization, hydrology, hydrogeology, sensitivity analysis, modelling, Environmental Decision Support Tool

\section{Software availability}

\begin{tabular}{|cl|}
\hline Name of software & KarstMod \\
Description & KarstMod is a collaborative project developed by the French SNO \\
& Karst. It provides an adjustable modelling platform for both the \\
& spring discharge simulation at karst outlets and hydrodynamic \\
& analysis of the compartments considered in the model. \\
& N. Mazzilli and D. Bertin \\
Developers & Free to the public (contact the developers) \\
Availability & karstmod@services.cnrs.fr \\
Contact address & 2014 \\
Year first available & Java Runtime Environment 1.8 \\
Software required & Java \\
Program language & 2.8 Mo \\
Package size & http://www. sokarst.org/ \\
Availability & 1.5 .5 \\
Current version & free of charge \\
Cost &
\end{tabular}

\section{Introduction}

Karst has been defined as "the medium where heterogeneity reaches is paroxysm" [18]. Indeed, high porosity and thus high permeability contrasts are typical of karst aquifers. These contrasts result in a duality of infiltration (either diffuse or concentrated) and of flow regimes (either laminar or turbulent). The karstification process itself, its self-organization ability [33] and the rapid evolution of karst conduits result in highly non-linear hydraulic connexions within, and global functionning of karst aquifers. With increasing demand for water, karst aquifers have grown more important as a resource. Modelling the rainfall - discharge relationship is an essential step in estimating the sustainable yield of karst aquifers but also in predicting the impacts of climatic or anthropogenic forcing on groundwater resources in the long term. Even so, characterization and modelling of karst aquifers remains a challenging task. Among the different modelling approaches,

\footnotetext{
* Corresponding author.

Email address: naomi.mazzilli@univ-avignon.fr (N. Mazzilli)
} 
lumped modelling is recognised as a major tool for analyzing hydrological processes and for managing water resource. These models are based on physically sound structures and equations selected by the modeler as representative of the main processes involved, together with semi-empirical processes [1]. This approach is particularly well suited to karst environments where knowledge of system geometry is usually difficult to gather $[8,12]$.

The parameters of lumped models cannot be determined directly from physical catchment characteristics, and thus parameter values must be estimated by calibration against observed data. The structure of compartment models is thus a trade-off between adaptability (the model must be able to represent a large variety of hydrological conditions) and parsimony (parameters must be identifiable and over-fitting must be prevented) [23]. Effective model development practices include careful sensitivity analysis and uncertainty assessment, to assess model performance and also model uncertainty and physical realism [32, 26]. An overview of sensitivity analysis and its link to model calibration and evaluation is provided in [25].

In this paper, we propose an adjustable modelling platform (KarstMod) for both the spring discharge simulation at karst outlets and hydrodynamic analysis of the compartments considered in the model. KarstMod provides a modular, user-friendly modelling environment for educational, research and operational purposes. It can reproduce the structure of conceptual lumped models of karst systems in the literature. The modularity of the platform allows a comparison of different hydrosystems through a single methodological approach. To promote valid modelling practices, the platform provides a variety of graphs and tools that facilitate improved understanding and insight into the behaviour of the models, and that detect possible flaws in structure and parameterization. Section 1 is a description of the platform. Section 2 illustrates KarstMod functionalities based on model application to the Fontaine de Vaucluse site of the SNO Karst network.

\section{Platform overview}

\subsection{Workflow}

In the first step, the user defines the model structure and fluxes using the graphical interface. As stated in the introduction, lumped models are based on physically sound structures and equations. The user may thus use his understanding of the main processes involved to define the model. However, we recommend a gradual complexification approach, with careful assessment of the influence of the selected compartment and fluxes on the resulting model behaviour and equifinality. The next step is to specify user-defined values of rainfall $(P)$, evapotranspiration $(E T)$ and reservoir pumping. The user also defines the performance measure and the warm-up, calibration and validation periods.

The model can run using user-specified parameter values ("run mode"), or in an automatic calibration mode. Most model outputs are available in both run and calibration modes (Fig. 1). The run mode may be especially useful for educational and learning purposes because it allows a direct analysis of the effect of the model parameters on the model results. Manual calibration may also leave the users (e.g. students) facing non-linearity of the model response. Calibration mode provides a systematic exploration of the parameters space. The outcomes of this exploration are the selection of the optimal parameter set for a selected performance measure, and a set of graphs that allow a first grasp of equifinality issues (see Section 1.4.2).

\subsection{Model structure and equations}

Karst aquifers can be consensually decomposed into an infiltration and a saturated zone [24, 29] :

- the infiltration zone comprises the soil and epikarst subsystem, which may store part of the infitrated water, plus the unsaturated subsystem, which connects the epikarst to the phreatic zone by drainage through a vertical network of fissures and conduits. It may be locally saturated.

- the saturated sub-system is split into a network of high permeability conduits and low permeability volumes with a high storage capacity.

The relative importance of these compartments in the hydrological functionning of the karst system depends on rock texture and structure and on the karst aquifer genesis history. Non-linearity affects the hydraulic connexions within and between the different compartments [15].

The modular structure proposed in KarstMod is based on this conceptual model, a thorough literature review of existing lumped models, and consideration of equifinality issues. In its most complete form, the platform offers 4 compartments organized on as a two-levels structure (Figure 2): (i) compartment E (higher level), (ii) compartments L, M and $\mathrm{C}$ (lower level). A priori, the higher level stands for the infiltration zone, and the lower level stands for the saturated zone where the compartments L, M, C stand for the different sub-systems of the saturated zone. However the user is free to assign model compartments to different conceptual model. In compartment E, the minimum water level can be either zero or lower (soil-available water content configuration, see Figure 2). To complement linear and non-linear water level - discharge laws which are traditionally used in lumped models, KarstMod proposes (i) an hysteretic discharge water level function which is meant to reproduce hysteretic dependence observed on wet-dry cycles in the vadose zone $[16,31]$, (ii) a exchange function proportional to the water level difference between two compartments, which is meant to reproduce matrix-conduit interactions as supported by direct observations of a variety of karst systems (e.g. [14, 2, 19]). The model nomenclature is detailed in appendix. 


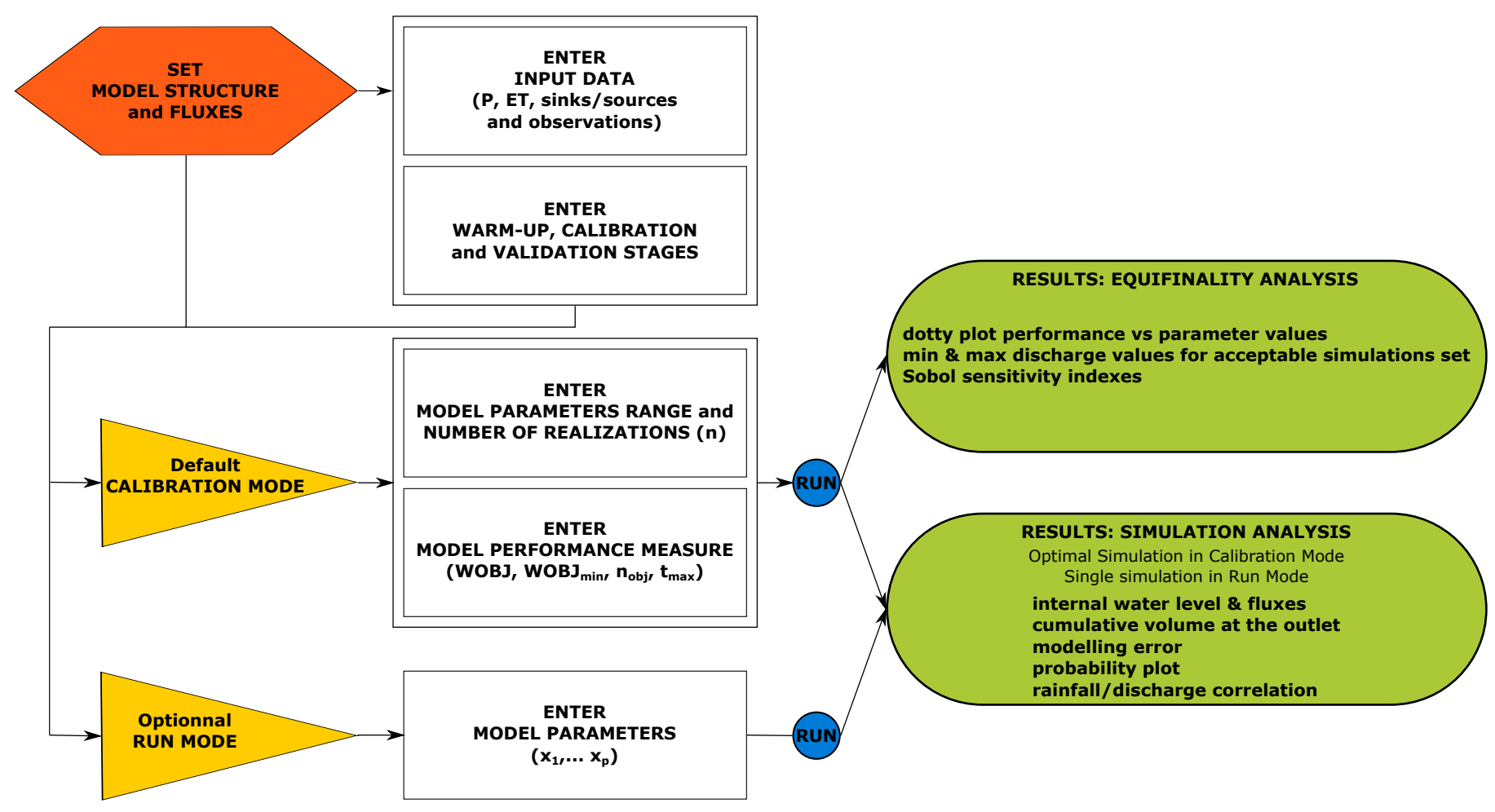

Figure 1: Synthetic workflow for the KarstMod platform. Hexagon, triangles, rectangles, circles and ellipsoids represent respectively building step on graphical interface, choice of simulation mode, input data and parameters, calculation step and results. Abbreviations are detailed in appendix 3.

The model has 5 balance equations:

$$
\begin{array}{rlr}
\frac{\mathrm{d} E}{d t} & =P-E T-Q_{l o s s}-Q_{E L}-Q_{E M}-Q_{E S}-Q_{E C}-Q_{h y E C}-Q_{h y E S} & \text { if } E \geq 0 \\
\frac{\mathrm{d} E}{d t} & =P-E T & \text { if } E_{\min }<E<0 \\
\frac{\mathrm{d} L}{d t} & =Q_{E L}-Q_{L S}-Q_{\text {pump }}^{L} & \\
\frac{\mathrm{d} M}{d t}=Q_{E M}-Q_{M C}-Q_{M S}-Q_{\text {pump }}^{M} & \\
\frac{\mathrm{d} C}{d t} & =Q_{E C}+Q_{h y E C}+Q_{M C}-Q_{C S}-Q_{\text {pump }}^{C} &
\end{array}
$$

where:

- $E, L, M$ and $C[\mathrm{~L}]$ are the water levels in the compartments E, L, M and C respectively,

- $E_{\min }[\mathrm{L}]$ is the minimum water level in compartment E,

- $P[\mathrm{~L} / \mathrm{T}]$ is the precipitation rate,

- $E T[\mathrm{~L} / \mathrm{T}]$ is the evapotranspiration rate,

- $Q_{\text {pump }}^{L}, Q_{\text {pump }}^{M}$ and $Q_{\text {pump }}^{C}[\mathrm{~L} / \mathrm{T}]$ are the discharge rates removed from compartment $\mathrm{L}, \mathrm{M}$ and C respectively, per unit surface area,

- $Q_{l o s s}, Q_{E M}, Q_{E S}, Q_{E C}, Q_{h y E C}, Q_{h y E S}, Q_{L S}, Q_{M S}, Q_{C S}, Q_{M C}[\mathrm{~L} / \mathrm{T}]$ are internal discharge rates per unit surface area.

The discharge at outlet $Q_{S}$ is given by:

$$
Q_{S}=R_{A} \times\left(Q_{E S}+Q_{L S}+Q_{M S}+Q_{C S}+Q_{h y E S}\right)-Q_{p u m p}^{S}
$$

where $R_{A}\left[\mathrm{~L}^{2}\right]$ is the recharge area of the catchment and $Q_{p u m p}^{S}[\mathrm{~L} / \mathrm{T}]$ is the discharge rate removed at the outlet per unit surface area. The internal fluxes are detailed in the user's guide. 


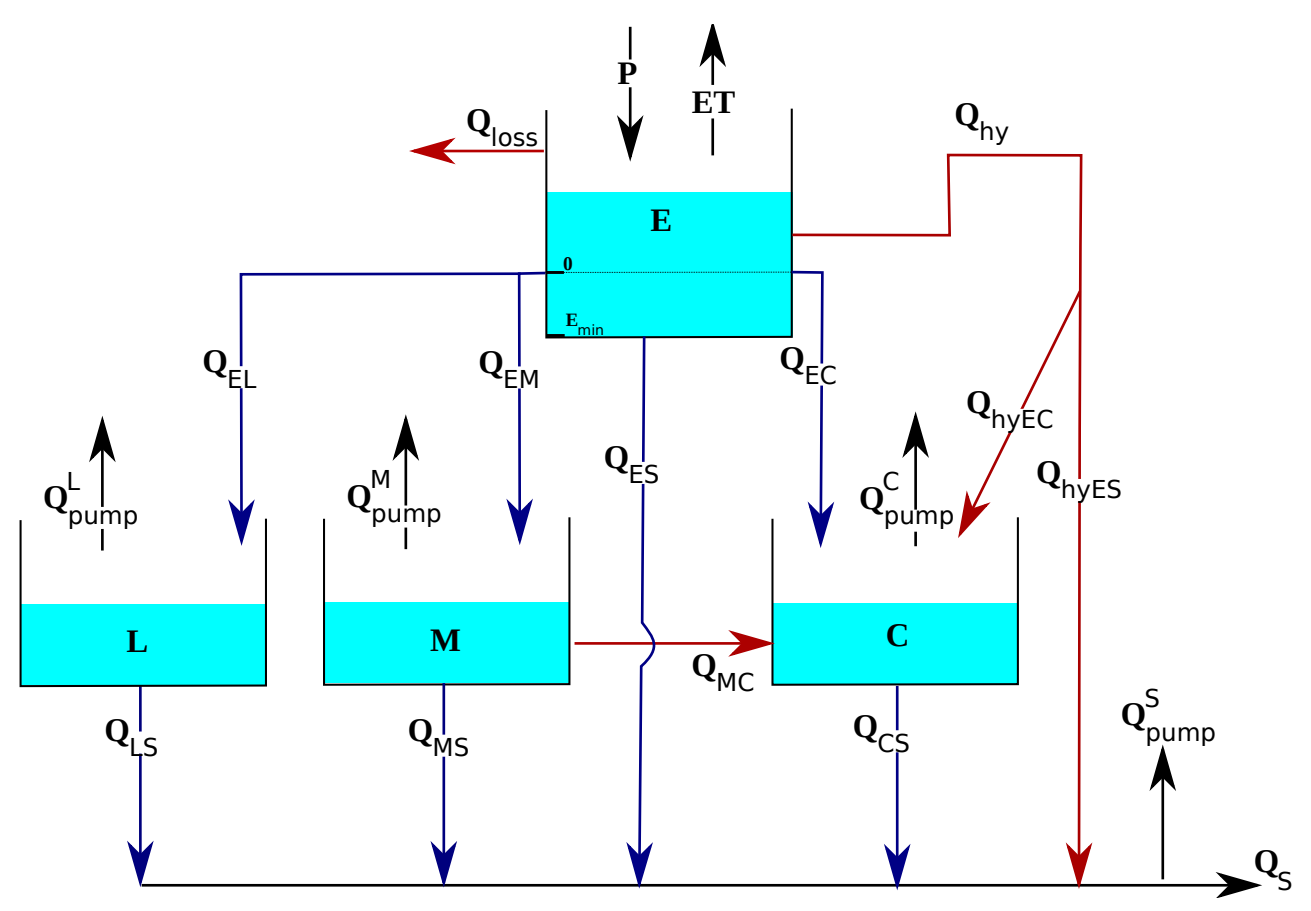

Figure 2: Structure of the modular platform. In this view all compartments and fluxes are activated, the minimum water level of $E_{m i n}<0$ is set for compartment $\mathrm{E}$, and the hysteretic function is used.

\subsection{Model calibration}

Warm-up, calibration and validation periods are controlled entirely by the user. The model provides the possibility to calibrate the initial water level in the activated compartments. Discontinuous calibration and validation periods are allowed.

The performance criteria proposed in KarstMod are the Nash-Sutcliffe efficiency NSE [22] and the modified Balance Error BE [23]. The user may apply the performance criteria to either the full range of the variable or to values above or below discharge thresholds. These functionalities make it possible to limit the influence of high discharge values in the NSE and to focus the analysis on either high or low flow periods.

KarstMod allows either single or multi-objective calibration approaches. The objective function used in the calibration procedure is either one of the performance criteria defined above, or an aggregated objective function defined as the weighted sum of two performance criteria. In the following, we use WOBJ as a generic notation for the selected objective function. The multi-objective problem is thus reduced to a scalarized one.

The model is calibrated using a quasi Monte-Carlo procedure, with a Sobol sequence sampling of the parameter space [30]. The procedure is stopped when either $n_{\max }$ parameter sets satisfying WOBJ greater than the user-defined threshold value $\mathrm{WOBJ}_{\text {min }}$ are collected, or when the elapsed simulation time reaches the maximum duration $t_{\text {max }}$ specified by the user. The user specifies both $\mathrm{WOBJ}_{\min }$ and $t_{\max }$.

The differential model equations 1 are solved using a fourth-order Runge-Kutta scheme and user-specified initial water levels in the selected compartments as initial conditions.

\subsection{Model outputs}

\subsubsection{Optimal simulation analysis}

The optimal parameter set is defined as the parameter set of the Sobol sequence sampling that yields the best model performance over the calibration period, with respect to the objective function WOBJ. The optimal simulation is the simulation that results from a model run, using the optimal parameter set. Regarding the optimal simulation, the following graphs are available : (i) internal and external variables and fluxes as a function of time, (ii) cumulative volumes at the outlet as a function of time, (iii) simulated mass balance per time step, (iv) simulation error as a function of time, (v) $Q_{S}$ versus $Q_{o b s}$ plot. These graphs make it possible to investigate the internal behaviour of the model and to detect possible drifts. The $Q_{S}$ versus $Q_{o b s}$ plot highlights simulation error variability during the simulation period. The following analyses are also available : (i) cumulative probability plots for the $\left(Q_{S}\right)$ and observed $\left(Q_{o b s}\right)$ discharges, (ii) auto-correlogram of $P$, (iii) cross-correlogram between $P$ and $Q_{S}, P$ and $Q_{o b s}, Q_{o b s}$ and $Q_{S}$. The discharge cumulative probability plots provide insight into processes that may influence the distribution law of discharge values, such as the existence of overflow springs, or the extra input or output of water coming from or towards a neighbouring system $[17,20]$. The simple and cross spectral analyses complete the study of correlogram functions providing information on the regulation time of the system, i.e. its inertia related to the nature of its storage and on the frequency of the phenomena that produce flow variations at the spring [17].

\subsubsection{Equifinality analysis}

Most environmental problems are ill-posed i.e. encounter issues about the unicity, identifiability and stability of the problem solution [6]. As a consequence, many different representations of the modelled system may be considered as 
equally acceptable [4]. In KarstMod, parametric equifinality can be investigated using the following tools:

- dotty plots of the values of the objective function (calibration period) against the values of the parameters $X_{i}$, for all the parameter sets of the Sobol sequence that satisfy WOBJ $>$ WOBJ $_{\text {min }}$. These plots provide a preliminary analysis of the distribution of the optimum values of each parameter.

- dotty plot of the values of the performance criteria used to define the agregated objective function, for all the parameter sets of the Sobol sequence that satisfy WOBJ $>$ WOBJ $_{m i n}$. These plots allow to investigate possible conflicts between the performance criteria (Pareto frontier) [11].

- variance-based, first-order $S_{i}$ and total $S_{T i}$ sensitivity indexes for the model parameters $X_{i}$. These indexes help estimating the influence of the parameters on the model output, and thus to detect over-parameterization.

The sensitivity indexes are related to the decomposition of the variance of the calibration variable (here, the discharge at the outlet) into terms either due to each parameter $i$ taken singularly (first order indices), or to the interactions between parameters [27]. Both indexes are calculated using the Sobol procedure described in [28].

KarstMod enables to use the simulation results from all parameter sets yielding WOBJ $>$ WOBJ min $_{\text {for }}$ the evaluation of the uncertainty on the simulation results. The approach is derived from the Regional Sensitivity Analysis (RSA) [13] and the Generalized Likelihood Uncertainty Estimation (GLUE) [3]. Instead of selecting a unique parameter set as the outcome of the calibration process, these methods consider that all parameter sets yielding satisfactory results over the calibration period (behavioural parameter sets) should be considered in the prediction process. The value of WOBJ over the calibration period is used as a likelihood measure for each behavioural parameter set. Based on this assumption, KarstMod produces the following simulation results:

- minimal and maximal discharge values simulated at time $t$ from the behavioural parameter sets. They help figure out the spread of the simulation results for the behavioural parameter sets.

- limits for the $90 \%$ confidence interval for the simulated discharge at time $t$.

- the most likely value of the simulated discharge, which is estimated considering both the objective function and the threshold value defined by the user to constrain the behavioural parameters set.

\section{Test Case}

The fontaine de Vaucluse spring is the only outlet of a $1115 \mathrm{~km}^{2}$ recharge area located South-East of France. Its mean flow rate is one of the highest in Europe (18 $\mathrm{m}^{3}$ over the 1966-2016 period). A 3-compartments lumped model of the rainfall-discharge relationship was proposed by Fleury et al [7]. The upper, soil compartment feeds two lower compartments that respectively simulate rapid and slow discharges. The authors used rainfall and temperature time series from four weather gauging stations to derive the meteorological $\mathrm{P}$ and ET inputs. Calibration was performed using the 1995-1996 hydrological year with no warm-up period, based on the Nash-Sutcliffe efficiency. We have been able to successfully reproduce the model structure (see Figure 3) and results from [7] using KarstMod. The platform also allows to test the sensitivity to the initial conditions. We let all parameters vary across a one order of magnitude range. Initial water levels were also allowed to vary. The calibration range for the initial water levels has ben set according to the observed water levels range during simulation. We ran the calibration with no warm-up period and with a one-year warm-up. Figure 4 shows the observed and simulated discharge, with the confidence interval for the simulated discharge. Figure 5 shows the sensitivity indexes. When no warm-up is used, the sensitivity to the initial conditions may be greater than the sensitivity to model parameter $k_{E C}$ which suggests that the calibration result is sensitive to the initial water levels. Using a one-year warm-up, the spread of the simulated discharge reduces in the first months of the calibration. The effect of the initial conditions on the calibration results becomes negligible as compared to the effect of the model parameters, as evidenced by the new sensitivity indexes. 


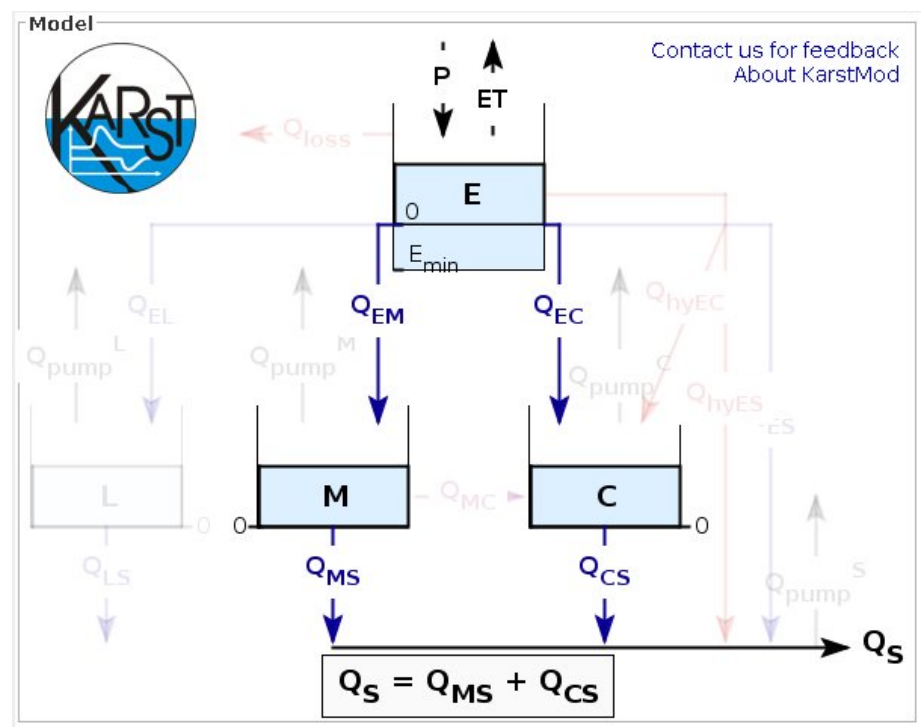

Figure 3: Model structure for the fontaine de Vaucluse hydrosystem
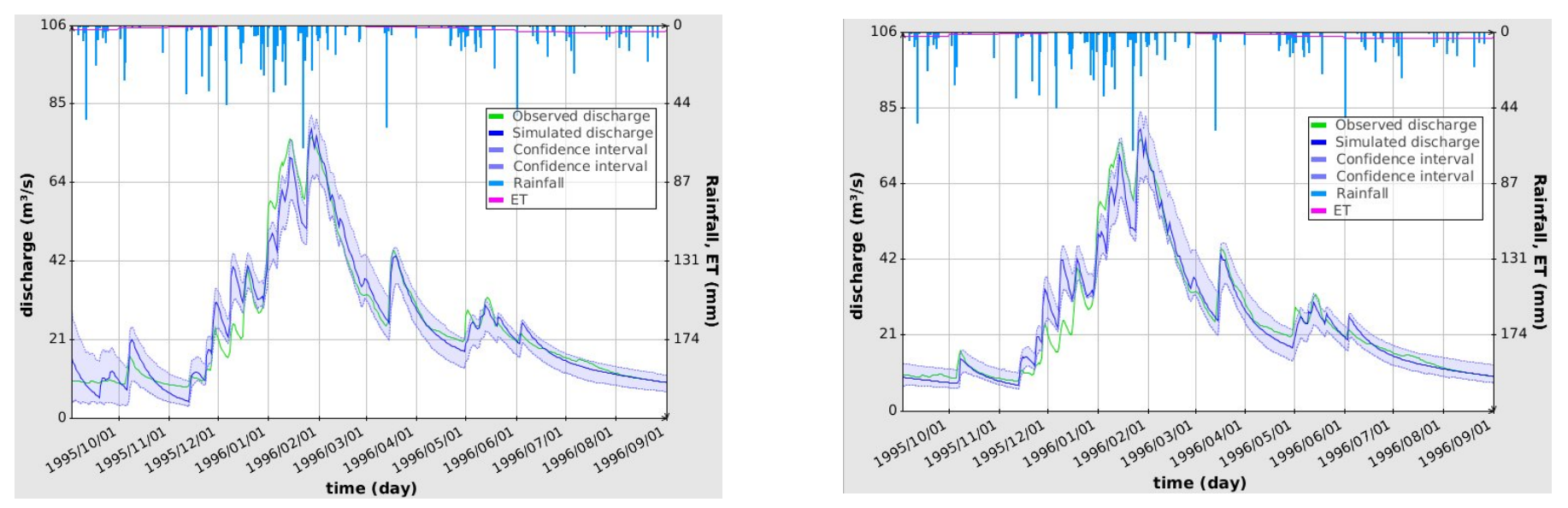

Figure 4: Simulation results for the behavioural parameter set (Nash Sutcliffe efficiency higher than 0.9) during calibration stage: (left) no warm-up period, (right) a one-year warm-up

\begin{tabular}{|l|l|l|}
\hline \multicolumn{1}{|c|}{ Parameter } & First-order index & Total-effect index - \\
\hline$k_{C S}$ & 0.312 & 0.487 \\
\hline$k_{E M}$ & 0.136 & 0.309 \\
\hline$k_{M S}$ & 0.053 & 0.134 \\
\hline$M_{0}$ & 0.061 & 0.12 \\
\hline$E_{0}$ & 0.067 & 0.111 \\
\hline$k_{E C}$ & 0.011 & 0.088 \\
\hline$C_{0}$ & 0.051 & 0.083 \\
\hline
\end{tabular}

\begin{tabular}{|l|l|l|}
\hline \multicolumn{1}{|c|}{ Parameter } & First-order index & Total-effect index - \\
\hline$k_{C S}$ & 0.313 & 0.659 \\
\hline$k_{E M}$ & 0.272 & 0.626 \\
\hline$k_{E C}$ & 0.004 & 0.126 \\
\hline$k_{M S}$ & 0.001 & 0.024 \\
\hline$M_{0}$ & $1.094 \mathrm{E}-4$ & 0.001 \\
\hline$E_{0}$ & $2.174 \mathrm{E}-5$ & $7.314 \mathrm{E}-5$ \\
\hline$C_{0}$ & $-2.012 \mathrm{E}-6$ & $4.793 \mathrm{E}-8$ \\
\hline
\end{tabular}

Figure 5: Sensitivity indexes for the model: (left) no warm-up period, (right)a one-year warm-up. 


\section{Conclusion}

The platform can be regarded as a useful tool for analyzing the hydrological processes for karst systems and for assessing the impact of management policies, for example when pumping is performed directly in the karst network. Although KarstMod has been designed for simulation of spring discharge at karst outlets, this platform could obviously be applied to any rainfall-runoff relationship modelling purpose. Thanks to its friendly interface, no programming skills are required to run the modelling platform. KarstMod will therefore prove especially useful for learning and occasional users, e.g. students. For research applications, KarstMod provides a primary analysis, easy exploration and comparison of models structures. Future developments of the platform include : (i) the consideration of the uncertainty on the measured input data in the calibration process, (ii) the proposition of additional transfer functions [10, e.g.].

\section{Acknowledgements}

This platform is developped within the framework of the KARST observatory network (SNO KARST) initiative from the INSU/CNRS, which aims to strenghten knowledge-sharing and promote cross-disciplinary reasearch on karst systems at the national scale.

\section{Nomenclature}

$\overline{Q_{o b s}} \quad$ mean value of $Q_{o b s}\left(\mathrm{~L}^{3} / \mathrm{T}\right)$

$\alpha_{A B} \quad$ general notation for the positive exponent of the discharge-water level function from compartment A to compartment B (assumed to be positive)

$\alpha_{\text {loss }} \quad$ positive exponent for the threshold loss function (-)

$\Delta E_{h y} \quad$ thresholds for the deactivation of the $Q_{h y}$ function (L)

$\varepsilon_{h y} \quad$ binary indicator of the activation of the hysteretic discharge

$A, B \quad$ general notation for the water level in compartment $\mathrm{A}, \mathrm{B}(\mathrm{L})$

$E_{h y} \quad$ thresholds for the activation of the $Q_{h y}$ function (L)

$E_{\text {loss }} \quad$ threshold for the activation of the $Q_{\text {loss }}$ function (L)

$E_{\text {min }}$ minimum water level in compartment E (L)

ET evapotranspiration rate $(\mathrm{L} / \mathrm{T})$

$k_{A B} \quad$ specific discharge coefficient for linear discharge law from compartment A to compartment B (L/T)

$k_{h y} \quad$ specific discharge coefficient of the hysteretic discharge $(\mathrm{L} / \mathrm{T})$

$k_{\text {loss }} \quad$ specific discharge coefficient for the $Q_{\text {loss }}$ function $(\mathrm{L} / \mathrm{T})$

$L_{\text {ref }} \quad$ reference length for normalisation of the water level of compartment $A$

$n_{o b j} \quad$ target number of simulations to achieve WOBJ $>$ WOBJ $_{\text {min }}$

$P \quad$ precipitation rate $(\mathrm{L} / \mathrm{T})$

$p \quad$ coefficient used to define $Q_{h y E C}$ as a function of $Q_{h y E S}$

$Q_{A B} \quad$ general notation for the discharge from compartment A to compartment B per unit surface area (L/T)

$Q_{\text {hyEC }} \quad$ hysteretic discharge from compartment E to compartment C per unit surface area $(\mathrm{L} / \mathrm{T})$

$Q_{h y E S} \quad$ hysteretic discharge from compartment E to the outlet S per unit surface area $(\mathrm{L} / \mathrm{T})$

$Q_{h y} \quad$ total hysteretic discharge from compartment E per unit surface area $(\mathrm{L} / \mathrm{T})$

$Q_{\text {loss }} \quad$ discharge lossed from compartment E per unit surface area $(\mathrm{L} / \mathrm{T})$

$Q_{\text {obs }} \quad$ observed discharge $\left(\mathrm{L}^{3} / \mathrm{T}\right)$

$Q_{\text {pump }}^{A} \quad$ discharge rates outtaken from compartment A per unit surface area (L)

$Q_{S} \quad$ discharge at the outlet $\left(\mathrm{L}^{3} / \mathrm{T}\right)$

$R_{A} \quad$ recharge area $\left(\mathrm{L}^{2}\right)$

sgn signum function 
$t_{\max } \quad$ maximum simulation duration $(\mathrm{T})$

$w \quad$ coefficient $\in[0,1]$ used for weighting the performance criteria (-)

A, B general notation for the compartments: either E, L, M, C, and the outlet: S

BE balance error (-)

NSE Nash-Sutcliffe efficiency model performance criteria

WOBJ objective function

$\mathrm{WOBJ}_{\min }$ threshold value of the objective function 
[1] Abbott M.B. \& Refsgaard J.C. 1996. Distributed hydrological modelling Kluwer Academic Publishers, 321

[2] Bailly-Comte V., Martin J., Jourde H., Screaton E., Pistre S. \& Langston A. 2010. Water exchange and pressure transfer between conduits and matrix and their influence on hydrodynamics of two karst aquifers with sinking streams. Journal of Hydrology, 386(1-4), 55-66

[3] Beven K. \& Binley A. 1992. The future of distributed models: Model calibration and uncertainty prediction. Hydrological Processes, John Wiley \& Sons Ltd, 6, 279-298

[4] Beven K. 2006. A manifesto for the equifinality thesis. Journal of Hydrology, 320, 18-36, doi:10.1016/j.jhydrol.2005.07.007

[5] Cognard-Plancq, A. L., Gevaudan, C., \& Emblanch, C. 2006. Historical monthly rainfall-runoff database on Fontaine de Vaucluse karst system: review and lessons. Karst, cambio climatico y aguas submediterraneas, Malaga, $465-475$.

[6] Ebel B. A. \& Loague K. 2006. Physics-based hydrologic-response simulation: Seeing through the fog of equifinality, doi:10.1002/hyp.6388. Hydrological Processes, 20, 2887-2900

[7] Fleury, P., Plagnes, V., \& Bakalowicz, M. 2007. Modelling of the functionning of karst aquifers with a reservoir model: Application to Fontaine de Vaucluse (South of France). Journal of Hydrology, 345(1), 38-49, doi:10.1016/j.jhydrol.2007.07.014

[8] Fleury P., Ladouche B., Conroux Y., Jourde H. \& Dörfliger N. 2009. Modelling the hydrologic functions of a karst aquifer under active water management - The Lez spring. Journal of Hydrology,365, 235-243, doi:10.1016/j.jhydrol.2008.11.037

[9] Guinot V., Cappelaere B., Delenne C. \& Ruelland D. 2011. Objective functions for conceptual hydrological model calibration: Theoretical analysis of distance and weak form-based functions. J. Hydrol. 401(1-13), doi:10.1016/j.jhydrol.2011.02.004

[10] Guinot V., Savéan M., Jourde H. \& Neppel L. 2015. Conceptual rainfall-runoff model with a two-parameter, infinite characteristic time transfer function. Hydrological Processes, 29: 4756-4778, doi:10.1002/hyp.10523

[11] Gupta H. V., Sorooshian S. \& Yapo P. O. 1998. Toward improved calibration of hydrologic models: Multiple and noncommensurable measures of information. Water Resources Research, 34, 751-763, doi:10.1029/97WR03495

[12] Hartmann A., Lange J., Aguado À.V., Mizyed N., Smiatek G. \& Kunstmann H. 2012. A multi-model approach for improved simulations of future water availability at a large Eastern Mediterranean karst spring. Journal of Hydrology, 468-469, 130-138, doi:10.1016/j.jhydrol.2012.08.024

[13] Hornberger G. \& Spear R. 1981. An approach to the preliminary analysis of environmental systems. Journal of Environmental Management, 12, 7-18

[14] Jeannin P.-Y. 1996. Structure et comportement hydraulique des aquifères karstiques PhD Thesis, University of Neuchâtel (Suisse)

[15] Labat D., Ababou R. \& Mangin A. 1999. Linear and nonlinear input/output models for karstic springflow and flood prediction at different time scales. Stochastic Environmental Research and Risk Assessment, 13(5), 337-364, doi: $10.1007 / \mathrm{s} 004770050055$

[16] Lehmann P., Stauffer F., Hinz C., Dury O. \& Fluhler H. 1998. Effect of hysteresis on water flow in a sand column with a fluctuating capillary fringe. Journal of Contaminant Hydrology 33, 81-100, doi:10.1016/S0169-7722(98)00066-7

[17] Mangin A. 1975. Contribution à l'étude hydrodynamique des aquifères karstique. PhD thesis, University of Dijon (France)

[18] de Marsily G., Delay F., Teles V. \& Schafmeister M. 1998. Some current methods to represent the heterogeneity of natural media in hydrogeology. Hydrogeology Journal, 6, 115-130

[19] Mazzilli N., Jourde H., Guinot V., Bailly-Comte V., Fleury P. 2011 Hydrological modelling of a karst aquifer under active groundwater management using a parsimonious conceptual model. Proceedings of the $\mathrm{H}_{2}$ Karst Conference held in Besançon, France (Sept. 1-3, 2011), 201

[20] Marsaud B., 1996. Structure et fonctionnement de la zone noyée des karsts à partir des résultats expérimentaux. Thèse de doctorat Orsay, Université Paris XI.

[21] Moussa R., 2010. When monstrosity can be beautiful while normality can be ugly: assessing the performance of event-based flood models. Hydrological Sciences Journal, 55(6), 1074-1084, doi:10.1080/02626667.2010.505893

[22] Nash J.E. \& Sutcliffe J., 1970. River flow forecasting through conceptual models : Part 1. A discussion of principles. Journal of Hydrology 10(3), 282-290 
[23] Perrin C., Michel C. \& Andreassian V. 2001. Does a large number of parameters enhance model performance ? Comparative assessment of common catchment model structures on 429 catchments. Journal of Hydrology 242(3-4), 275-301, doi:10.1016/S0022-1694(00)00393-0

[24] Perrin C., Michel C., Andréassian V. 2003. Improvement of a parsimonious model for streamflow simulation. Journal of Hydrology 279(1-4), 275-289, doi:10.1016/S0022-1694(03)00225-7

[25] Pianosi F., Beven K., Freer J., Hall J., Rougier J., Stephenson D., Wagener T. 2016. Sensitivity analysis of environmental models: A systematic review with practical workflow. Environmental Modelling \& Software. 79, 214-232, doi:10.1016/j.envsoft.2016.02.008

[26] Refsgaard J.C., van der Sluijs J.P., Brown J. \& van der Keur P. 2006. A framework for dealing with uncertainty due to model structure error. Advances in Water Resources, 29, 1586-1597, doi:10.1016/j.advwatres.2005.11.013

[27] Saltelli A., Ratto, M., Andres T., Campolongo F., Cariboni J., Gatelli D., Saisana M. \& Tarantola S. 2008. Global Sensitivity Analysis. The Primer, John Wiley \& Sons

[28] Saltelli A. 2002. Making best use of model evaluations to compute sensitivity indices. Computer Physics Communications 145, 280-297, doi:10.1016/S0010-4655(02)00280-1

[29] Sauter M., Florea L. J., Covington M., Goabrovsek F., Gao Y., Green, R., Gulley J., Harmon R., Herman E., Jeannin P.-Y., Jones W. K., Kincaid T., Moore P., Mylroie, J., Sasowsky I. D., Screaton E. \& Wicks C. 2008. Focus group on karst hydrology - conceptual models, aquifer characterization, and numerical modelling. Frontiers of Karst Research, M. Sasowsky I., White W. \& Martin, J. (Eds.), 2008, 77-81

[30] Sobol I., 1977. Uniformly Distributed Sequences with an Additional Uniform Property. USSR Computational Mathematics and Mathematical Physics, 16, 236-242

[31] Tritz S., Guinot, V. \& Jourde, H. 2011. Modelling the behaviour of a karst system catchment using non linear hysteretic conceptual. model Journal of Hydrology, 397, 250-262, doi:10.1016/j.jhydrol.2010.12.001

[32] Wagener T., McIntyre N., Lees M. J., Wheater H.S. \& Gupta H.V. 2003. Towards reduced uncertainty in conceptual rainfall-runoff modelling: Dynamic identifiability analysis. Hydrological Processes, 2003, 17, 455-476, doi:10.1002/hyp.1135

[33] Worthington S.R.H. \& Ford D.C. (2009). Self-Organized Permeability in Carbonate Aquifers. Ground Water, 47: 326-336. doi:10.1111/j.1745-6584.2009.00551.x 